\title{
O ENSINO PROFISSIONALIZANTE NA SOCIEDADE MODERNA INDUSTRIAL: UM OLHAR HISTÓRICO
}

Vocational education in modern industrial society: a historical sight

\author{
Roberto Evair Falcioni \\ Mário Lopes Amorim
}

\section{Resumo}

Este artigo pretende retratar historicamente, determinadas experiências de ensinos profissionais ao longo da formação da sociedade moderna, descrevendo suas características na relação educação, trabalho e sociedade. O objetivo central é apontar em recortes específicos de educação profissional, a existência de algo em comum ocasionado pela herança pós Revolução Industrial: a manutenção e reprodução das relações de classes e do sistema capitalista vigente, privilegiando uma minoria nos aspectos políticos, sociais e econômicos e, consequentemente, excluindo uma maioria das esferas descritas. A escrita se baseará numa metodologia histórica processual, partindo do ensino profissional francês do século XIX, percorrendo por outros recortes específicos até chegar à Lei n. 5.692/71. Como resultado tem se a idéia de que o ensino profissional foi utilizado para garantir o funcionamento da estrutura social capitalista, baseado numa sociedade exploratória e desigual.

Palavras-chave: Educação profissionalizante; Relações de classes; Modos de produção capitalista; Dualidade educacional; Lei n. 5.692/71.

\section{Abstract}

This article intends to depict certain experiences of vocational education historically, through the course of development of modern society, describing its main characteristics in the education-work-society relationship. The core objective is to show, through specific events of vocational education, the 
existence of something in common between them, caused by their postIndustrial-Revolution legacy: maintenance, guarantee and reproduction of class relations and an effective capitalist system that benefits the minority in politics, social and economic aspects and that consequently excludes most of the spheres described. Thus, this paper will be based on a procedural historical methodology patterned after the French vocational education of the $19^{\text {th }}$ century, across other specific events, until reaching Law \# 5692/71. As a result, there is a notion that vocational education was used to ensure the functioning of the capitalist social structure, based on an exploitative society of unequalites.

Keywords: Vocational Education; Class Relations; Forms of Capitalist Production; Education Dualism; Law \#5692/71.

\section{INTRODUÇÃO}

O que está em tela neste artigo é apontar como o sistema social capitalista atuou e atua (por meio dos seus personagens, através das relações de classes), na manipulação dos mecanismos (como educação, governo, meios de produção, sistemas repressivos e punitivos como o exército e a polícia) para a articulação dos aspectos econômico, político e social objetivando sua auto-reprodutibilidade, deixando intocada e garantida a reprodução da sociedade de classes burguesa desigual e exploradora. Para tanto, serão analisados momentos específicos de ensinos profissionalizantes implantados, tendo como prioridade encontrar os interesses do grupo dominante de cada período, implícitos nestes modelos de educação profissional.

O artigo partirá de uma descrição sobre a trama que envolve o contexto da Revolução Industrial, e o surgimento da educação profissionalizante, perpassando pelo processo de formação da sociedade moderna, para então analisar casos específicos de educação profissionalizante no século XX no Brasil, com o Sistema Senai e a Lei n. 5.692/71.

Tratando-se apenas de alguns casos específicos de educação profissionalizante, o autor tem a consciência e transmite ao leitor que este estudo não se trata de uma análise histórica totalizante do ensino 
profissionalizante, visto que seria um objetivo impossível de se alcançar num artigo acadêmico.

\section{Ensino Profissional no contexto pós Revolução Industrial}

O presente artigo tem como tema central a experiência do ensino profissionalizante com a Lei n. 5.692/71. Não obstante, será delineado um modelo de análise histórica pautado em descrever determinados recortes de casos existentes da educação profissional, partindo do contexto da era napoleônica com a educação profissionalizante francesa do início do século XIX, até chegar ao acontecimento da promulgação da Lei n. 5.692/71 e seus impactos no sistema educacional brasileiro na década de 1970 .

O que chama a atenção é o fato de serem portadoras de influências pós Revolução Industrial, ou seja, um modelo de educação atrelado com os modos de produção capitalista industrial, relações de classes e utilização classista através da política no sistema educacional. Portanto, o desafio acadêmico desta escrita baseia-se na intenção de produzir um estudo processual histórico da educação profissional, tendo por hipótese central a idéia de indicar nestas experiências um ponto convergente entre elas: o fato de serem resultado da consolidação do sistema capitalista industrial e das relações de classes, excluindo uma maioria e privilegiando uma minoria na sociedade através da educação.

\section{O ensino profissional francês do século XIX: a Escola Central}

O ponto de partida escolhido para a problematização processual histórica de determinadas experiências do ensino profissionalizante, foram as instituições de ensino profissionalizante da era napoleônica. A justificativa para a apresentação do sistema de ensino francês dos séculos passados se encontra muito bem argumentado por Rui Gama (1987), quando descreveu a influência do sistema de ensino francês nos outros países entre os séculos XVI até XIX: 
A educação foi alvo de muita atenção do governo de Napoleão, que fundou a Escola Normal, a Escola Politécnica, em 1808 e 1811 fundou a Universidade da França e também criou em 1802 um sistema de escolas secundárias chamadas Lycées (DAY, 1987, p. 21). Esta questão deixa claro o embasamento da justificativa do início da problematização entre a relação consolidação do sistema econômico fabril e a conseqüente necessidade de mão de obra qualificada, fato suprido pela profissionalização, isto é, foi somente a partir do contexto pós Revolução Industrial que países mais avançados econômico, social e industrialmente tiveram em seu sistema educacional o surgimento do ensino profissionalizante.

Nesta esteira, a análise sobre a instituição de ensino Escola Central de Paris possibilitará apontar como era as características do que poderia ser chamado de ensino profissionalizante do século XIX, isto é possível porque a Escola Central estava comprometida com a "formação de engenheiros e técnicos para a indústria, principalmente para as máquinas e indústrias metalúrgicas" (DAY, 1987, p. 12). Apesar da França no século XIX não estar em total comparação com o desenvolvimento superior da Inglaterra no campo da indústria, no que tange ao nível de investimento, desenvolvimento e estrutura, a educação e a ciência francesa era, de longe, mais avançada que a inglesa (HOBSBAWN, 1982, p. 47).

Inseridos no contexto do desenvolvimento industrial da Europa do século XIX, bem observaram os filósofos Karl Marx e Friedrich Engels (1983, p. 65), que "do sistema fabril [...] brotou o germe a educação do futuro". Ou seja, tanto Marx quanto Engels (1983) tinham a convicção de que o surgimento e a existência da fábrica forçaram o engendramento, lento e paulatino, de uma popularização do acesso à educação.

A Escola Central organizada de forma privada em 1829 formou um novo tipo de homem tecnológico, em meio ao surgimento de uma rápida expansão industrial, o engenheiro civil. A Escola Central transformou a elite numa classe tecnológica, já a classe popular no século XIX mal tinha acesso à educação mínima e, este mínimo estava surgindo devido às leis da fábrica relativas à educação, principalmente das crianças, gênero que formava um plantel de trabalhadores fabril considerável (MARX, 1983, p. 61). Portanto, os 
estudantes centraliens vinham da alta classe industrial, mas uma especificidade interessante a apontar é que apesar de serem de origem social abastada, eram contratados em maior número como trabalhadores assalariados, o que deixa claro que a classe alta se utilizava da educação profissionalizante enquanto meio de garantia e manutenção da classe.

Em 1857, a Escola Central tornou-se pública, situação que indiretamente demonstra a existência na França de um governo capitalista consolidado interessado na educação enquanto meio de ascensão social. No século XIX, a Escola não tinha muito a pretensão acadêmica de estudar as conseqüências da industrialização no âmbito social, diferente de outra instituição de peso do período, a Politécnica era mais engajada com questões sociais como levar ciência à classe trabalhadora (DAY, 1987, p. 15). No século XX, generalizando para resumir o estudo, mas consciente da artificialidade da afirmação, mudou a origem classista dos estudantes centraliens, de estudantes da classe alta industrial para filhos de comerciantes, funcionários públicos e privados, como também filhos de artesãos (DAY, 1987).

Apresentado uma instituição de ensino profissional na França do século, pôde ser distinguido um ponto importante da análise histórica sobre a Escola Central: o surgimento da educação profissionalizante estava intimamente atrelado com o processo de consolidação do sistema capitalista industrial no país e, consequentemente, com os interesses classistas da burguesia em ascensão no poder.

\section{Ensino Profissional no Brasil: um olhar histórico}

No Brasil, pode se dizer que o processo de consolidação do sistema capitalista ocorreu posteriormente à existência do que poderia ser chamado de ensino profissionalizante.

Em suma, as diversas implantações de modelos de educação profissionalizante no Brasil, têm vários pontos divergentes entre eles, tanto em relação à implantação quanto ao modelo implantado, porém, algo leva a crer que exista inegavelmente um ponto em comum nas diversas experiências profissionalizantes: a influência de interesses do grupo dirigente no poder diante dos modelos de ensino, manifestado através das propostas políticas, como também nas respostas de setores da sociedade diante de necessidades classistas. 
O ensino profissional na década de 1940: SENAI

Em janeiro de 1942, sob o Decreto-Lei n. 4048, Getulio Vargas e os ministros da educação e do trabalho assinaram a promulgação que autorizava a criação do Serviço Nacional de Aprendizagem Industrial - Senai (WEINSTEIN, 2000, p. 118).

Para Luiz Antonio Cunha (2000) o Senai foi um exemplo de política patrimonialista onde as esferas públicas e privadas foram marcadas pela ambiguidade, afinal, a instituição Senai foi imposto pelo Estado Novo à classe burguesa, tanto que "os empresários reagiram fortemente ao projeto varguista de instituir uma contribuição compulsória para financiar a formação profissional de operários" (CUNHA, 2000, p. 46). Patrimonialista porque o Estado Novo assumiu uma postura de protetor, indutor e representante de interesses privados, bem como atuou como um verdadeiro árbitro na luta de classes entre patrões e empregados, na organização de um meio de produção harmônico e disciplinado, características da preocupação estatal com a "paz social" (CUNHA, 2000).

A partir do Estado Novo (1937-1945), a formação profissional tomou impulso, o motivo era obter o apoio da classe trabalhadora e média diante do governo recém imposto. Mas o período ajuda a entender a preocupação do governo diante da educação profissional, uma vez que, a Segunda Guerra Mundial era um momento de boa expectativa econômica para os industriais brasileiros. Percebem-se dois fatos importantes neste ponto contextual, o primeiro era o problema na década de $1930 \mathrm{com}$ a falta de mão de obra qualificada nas indústrias, também ocasionado pela dificuldade de trabalhadores estrangeiros permanecerem no Brasil ou até mesmo virem para o país (WEINSTEIN, 2000, p. 104); a segunda questão era o próprio momento de guerra mundial, $\mathrm{o}$ acontecimento refletiu diretamente na economia brasileira, os "industriais estavam desfrutando de um boom [aumento] na produção e no consumo" (WEINSTEIN, 2000, p. 122).

Para solucionar o problema da falta de mão de obra qualificada nas indústrias, juntamente com a intenção não manifesta do governo de Getúlio Vargas em obter o apoio popular perante sua posição no poder vigente de forma autoritária e antidemocrática, surgia o sistema Senai. 
Algo que chamou a atenção nas escolas Senai, tanto pelos olhos de Cunha (2000) quanto os de Weinstein (2000), foi a preocupação em adotar (e atuou como tal) com uma filosofia que valorizasse as normas, regras, disciplina, padrões de comportamentos, tudo visando mecanizar o aluno, domesticando-o para da melhor forma possível adaptá-lo ao mundo do trabalho industrial. Tanto que, a intenção consciente foi traduzir o Senai enquanto uma extensão da indústria, "desde o método taylorista de ensino até hierarquia, ordens e ambiente" (CUNHA, 2000 p. 69). O Senai baseava seu ensino num modelo de muita disciplina, controle e, se houvesse a necessidade, punição.

Estas foram situações e atividades do Senai que diante da classe dominante (industriais) muito colaborou com eles: uma formação profissionalizante sem engajamento político, sem um estudo aos aprendizes que contribuísse para uma visão crítica das relações de classes e da natureza dos modos de produção e, principalmente, formação de mão de obra qualificada barata para as necessidades momentâneas das novas tecnologias industriais (CUNHA, 2000).

\section{Educação e Regime Militar: Lei n. 5.692/71 seus objetivos e impactos}

A última etapa desta análise histórica do ensino profissionalizante no Brasil se refere à implantação obrigatória do ensino profissionalizante em nível médio com a Lei n. 5.692/71.

A partir da década de 1950, o Brasil foi palco de sérias transformações no âmbito econômico que refletiram diretamente nas relações de classes, na ordem social e política até então vigente. A educação brasileira sofreu sérios impactos com uma considerada crise na estrutura educacional, esta crise foi, por sua vez, resultado das mudanças trazidas "com a aplicação do Plano de Metas, do programa de governo de Juscelino Kubitschek, quando o Brasil passou a ingressar numa nova fase de sua economia industrial" (AMORIM, 2004 , p. 259), onde houve a mudança de um capitalismo liberal (com várias pequenas empresas de empreendedores brasileiros), para um capitalismo monopolista, baseado num modelo econômico formado por poucas, mas grandes empresas internacionais (CUNHA, 1977). 
Antes da década de 1950, a classe média utilizava enquanto meio de ascensão social os pequenos negócios: "mecanismos de constituição/investimento/reprodução de capital" (CUNHA, 1977, 105). O capitalismo monopolista sufocou as pequenas empresas, obrigando a classe média a voltar sua atenção para a educação enquanto novo meio de ascensão social. Por sua vez, a valorização da educação pela classe média, quando se tornou seu novo meio de ascensão social, ocasionou um aumento significativo nas matrículas para o ensino em geral principalmente para a educação superior. Contudo, o sistema educacional não estava esperando este aumento expressivo de alunos, o que produziu, por exemplo, um impasse entre o número de vagas ofertadas no ensino superior com a demanda de alunos (CUNHA, 1977).

Portanto, o resultado da crise educacional da década de 1950 no Brasil foi um verdadeiro inchaço, um aumento expressivo em todos os níveis educacionais, em particular no ensino superior, concomitante com a mudança mencionada na economia (CUNHA, 1977, 113), esse foi o resultado da crise educacional proporcionada pela mudança na natureza do sistema capitalista no país.

Na década de 1960 o Governo Militar teve que atuar de duas formas para resolver a crise educacional, de um lado tentou aumentar as vagas existentes levando em consideração as exigências e reivindicações da classe média, por outro, tentou conter o acesso da população ao ensino superior, acreditando que a crise educacional era resultado de uma falta de formação específica profissionalizante no sistema escolar anterior (nível médio) ao ensino superior. Tanto que, o governo militar tinha em seu discurso a crença da falta de mão de obra qualificada no mercado de trabalho (CUNHA, 1977).

A crise ameaçava a segurança nacional, ameaçava o domínio político militar, uma vez que, o "descontentamento estudantil perante a falta de vagas possibilitava situações de atuações políticas estudantis que o Estado não poderia ter controle" (FREITAG, 1986, p. 87). Este é o verdadeiro sentido da crise.

Nesta ótica, a Lei n. 5.692/71 foi idealizada para atuar na superação da crise educacional da seguinte maneira: na tentativa de conter a continuidade do estudo do aluno ao ensino superior, com a implantação obrigatória (teoricamente) do ensino profissionalizante em nível médio, onde formaria o aluno para ser inserido "satisfatoriamente" no mercado de trabalho logo após sua formação em nível médio. 
Sendo assim, não necessitaria da formação acadêmica para sua realização profissional, despreocupando o aluno com seu futuro na estrutura social classista, fazendo com que "o indivíduo deixasse de lado a luta de classes e a preocupação em servir de porta voz da classe dominada" (FREITAG, 1986, p. 87).

A intenção não manifestada na aplicação da Lei n. 5.692/71 era atribuir uma nova função ao nível médio que, a partir da reforma educacional seria profissionalizante: "conter a demanda crescente de vagas no ensino superior" (CUNHA, 1977, p. 144). Além do ensino profissionalizante em nível médio de forma compulsória, a Lei n. 5.692/71 também previa a extensão da obrigatoriedade escolar de 4 para 8 anos (ROMANELLI, 1978).

Entretanto, a função de conter a demanda ao ensino superior, almejada pelo governo com a obrigatoriedade do ensino profissionalizante em nível médio falhou, assim, a expectativa de solucionar a crise educacional através da terminalidade no ensino médio foi um verdadeiro fracasso.

Os motivos do fracasso foram vários, dentre eles, estava a questão do limite de recursos, "o Estado não investiu de forma suficiente na expansão e equipamento da rede escolar" (GERMANO, 2000, p. 185). Sem contar o fator que o ensino profissional exigiria um custo de $60 \%$ maior em comparação com o ensino geral. Houve também certa resistência por parte das empresas em absorver a mão de obra formada neste ensino, uma das fontes que embasam tal afirmação era o relatório do Banco Mundial de 1975, onde se explicitava que "as indústrias e empresas exigiam cada vez mais, trabalhadores com sólida - mesmo que básica - formação em matemática, língua e ciência" (GERMANO, 2000, p. 185).

Por último seria o fracasso das expectativas governamentais em estancar para a universidade a demanda educacional, através do ensino profissionalizante, que se constituiria através de um caráter de terminalidade, esta terminalidade nunca ocorreu, os estudantes da classe média continuaram utilizando o ensino técnico e profissionalizante enquanto propedêutico.

O grupo social que mais sentiu os impactos na esfera econômica com o ensino profissionalizante obrigatório em nível médio foi a classe baixa, pois a reforma educacional acabou fortalecendo a rede privada, desqualificando a rede pública no que tange ao caráter de continuidade, e surgindo um novo tipo de escola exclusivamente propedêutica, os chamados "cursinhos" prévestibulares (GERMANO, 2000, p. 190). 
A minoria (elitista) continuou com um ensino propedêutico, principalmente na rede privada, coube a maioria um ensino de má qualidade que não preparava nem ao mercado de trabalho, muito menos à continuidade dos estudos que por ventura encaminhasse ao ensino superior, resultado? Continuação do uso da educação tanto profissional quanto geral pela classe média enquanto meio de ascensão social, acentuação da dualidade no sistema educacional, engessamento da estrutura social (criando complicadores para uma hipotética ascensão social do indivíduo da classe baixa), reprodução da desigualdade social, econômica e política e, reprodução das relações de classes vigente baseado numa minoria privilegiada e numa maioria excluída.

\section{Resultados e discussão}

A formação da sociedade moderna trouxe consigo a instituição de novas esferas sociais (como a educação profissionalizante), com o objetivo de servir ao novo modelo econômico e garantir o funcionamento pacífico desta nova estrutura social, baseado "em dois grandes blocos inimigos, em duas grandes classes que se enfrentam diretamente: a burguesia e o proletariado" (MARX, 2001, p. 24).

Neste viés a constituição da sociedade moderna sagrou a classe burguesa enquanto detentora do poder econômico, político e social. Porém, neste processo de coroamento do poder da burguesia, foi necessária a utilização de várias estratégias para a garantia da reprodução e perpetuação das relações de classes dentro de um sistema capitalista proposto na divisão entre detentores dos meios de produção e seus trabalhadores.

A educação profissional foi uma das esferas institucionais onde a implantação destas estratégias ficou evidente. Muito além da imposição disciplinadora do uso do tempo econômico, cronológico e pontual nas escolas, as mudanças sofridas no sistema educacional ao longo dos séculos XIX e XX, representaram interesses dos grupos dominantes.

A reprodução da classe trabalhadora através de uma educação profissional desprovida de um conteúdo crítico, analítico social, no intuito de camuflar a luta de classes, acaba por ter a dupla função de reproduzir o poder econômico, político e social da classe burguesa, e a desigualdade entre as classes (MARX, 1983). 


\section{Considerações finais}

Mediante o exposto, o ensino profissionalizante ao longo da história se revestiu de uma roupagem com diferentes discursos, objetivos, dentre outros, porém, um ponto é inegavelmente comum em todas as experiências profissionais: a manutenção, garantia e reprodução das relações de classes e do sistema capitalista vigente. Ora, essa função implícita não está preocupada com igualdade política, social e muito menos econômica, o resultado é sua atuação privilegiando certos grupos sociais em detrimento de outros.

Ao longo do Artigo delineamos um sistema de ensino profissionalizante do século XIX na França, e direcionando para uma análise sobre o século XX no Brasil com o Sistema Senai e a Lei n. 5.692/71. Todos esses recortes de acontecimentos ligados ao ensino profissionalizante na sociedade moderna, tiveram algo em comum: serviram aos interesses sociais, políticos e econômicos dos grupos dominantes no poder de cada período.

Esta foi a problematização em torno do sistema Senai criado na década de 1942, e da Lei n. 5.692 do ano de 1971. O foco dado foi baseado na afirmação de que é característica da sociedade capitalista a utilização da educação como instrumento de poder, dominação e perpetuação de domínio social, político e econômico.

Neste prisma, a Lei n. 5.692/71 teve função de atuar na garantia do controle social, da ordem, da "harmonia entre as classes", da reprodução do sistema econômico capitalista nas relações de classes. Portanto, muito mais do que inocentemente formar o profissional necessário para atender à demanda das novas indústrias multinacionais no Brasil, o Decreto Lei $\mathrm{n}$. 5.692/71, estabelecendo a tentativa de obrigatoriedade do ensino profissionalizante em nível médio, previa assegurar o funcionamento pacífico da estrutura social capitalista do Brasil, através da reprodução da classe trabalhadora sem uma formação crítica, questionadora, também formando o emprego da classe média urbana e por último garantindo o domínio da elite (sob a denominação de Regime Militar) no poder.

A educação profissional e geral, desde o século XIX teve um aumento no seu acesso, e de forma inédita, apesar de ser há pouco tempo, a classe baixa pôde começar a participar de um processo social no qual a formação educacional acadêmica está presente. 
Contudo, esta "democratização" não vem trazendo igualdade de oportunidades para todos, o que significa dizer que a inserção da classe popular no mundo educacional ocasionou uma série de questões como falta de qualidade no ensino, na estrutura escolar, o aprofundamento da desigualdade educacional, onde está nítida a dualidade do ensino entre a educação terminal, sem continuidade, sem ascensão social para a maioria, e uma educação elitista, propedêutica, voltada para a garantia da posição social elitista da minoria (GERMANO, 2000), dentre outros pontos.

Assim, este artigo se encerra, não esgotando um assunto que ainda merece muita atenção entre a relação educação profissionalizante, modos de produção industrial e relações de classes, mas deixando um novo caminho a ser problematizado: Como as esferas sociais responderam diante dessas estratégias hegemônicas dos grupos sociais no poder?

\section{Referências}

AMORIM, Mário Lopes. Da Escola Técnica de Curitiba à Escola Técnica Federal do Paraná: projeto de formação de uma aristocracia do trabalho (1942-1963). 2004. 277 f. Tese (Doutorado História da Educação e Historiografia) - Programa de Pós Graduação em Educação, Faculdade de Educação da Universidade de São Paulo, São Paulo, 2004.

CUNHA, Luiz Antônio Rodrigues. O Ensino Profissional na irradiação do Industrialismo. São Paulo: UNESP, 2000.

CUNHA, Luiz Antônio Rodrigues. O Ensino de Ofícios Artesanais e Manufatureiros no Brasil Escravocrata. 2. ed. São Paulo: Unesp, 2005.

CUNHA, Luiz Antônio Rodrigues. Política educacional no Brasil: a profissionalização no ensino médio. Rio de Janeiro: Eldorado, 1977.

DAY, Charles. Education for the Industrial World: the Ecoles d'Arts et Metiers and the Rise of French Industrial Engineering. Cambridge, Mass: MIT Press, 1987. 
FREITAG, Bárbara. Escola, Estado e Sociedade. 6. ed. São Paulo: Moraes, 1986.

GAMA, Ruy. A Tecnologia e o Trabalho na História. São Paulo: Nobel/EDUSP, 1987.

GERMANO, José Willington. Estado Militar e Educação no Brasil. 3. Ed. São Paulo: Cortez, 2000.

HOBSBAWN, E. J. A Era das Revoluções. 1789-1848. 2. ed. Lisboa: Editorial Presença, 1982.

MARX, Karl. ENGELS, Friedrich. Textos sobre Educação e Ensino. São Paulo: Moraes, 1983.

MARX, Karl. ENGELS, Friedrich. Manifesto Comunista 1848. Porto Alegre: L\&PM POCKET, 2001.

ROMANELLI, Otaíza de Oliveira. História da educação no Brasil. Rio de Janeiro: Vozes, 1978.

WEINSTEIN, Bárbara. (Re) Formação da Classe Trabalhadora no Brasil (1920-1964). São Paulo: Cortez: Universidade de São Francisco, 2000. 